F.N. Lion-Cachet

\title{
DIE BEKLEMTONING VAN \\ DIE GESLAGTE OF GESLAGSLYSTE IN GENESIS
}

Julius Wellhausen het reeds die belangrikheid van die geslagte of geslagslyste (toledot) besef en het in sy onderskeiding van die verskillende bronne toledot as een van die karakteristjeke woorde van die P-dokument beskou. P het dit later toegevoeg om die inhoud van die uit bronne saamgestelde Pentateug en in die besonder Genesis skematies te konstrueer. Die toledot-formule kom dan normaalweg aan die begin van sekere P-stukke voor. Die uitsondering is Gen.1:4a, waar dit die slotsin van 'n P-stuk vorm. As motivering vir hierdie afwyking is later verskeie oplossings aan die hand gedoen, bv. dat so ' $n$ formule nie by die forse inleiding soos in Gen.1:1 gevind tuishoort use. Die verbinding van toledot met die P-stukke is van verskillende kante bevraagteken (o.a. Eerdmans, Löhr, Volz, Smend, Eichrodt ens. - cf. Külling, 1964:216-26). Nadat Külling (ibid., p. 217) 'n deeglike studie in dié verband onderneem het, het hy afdoende bewys dat die toledot-formules nie aan die P-stukke verbind mag word nie, en dit was daarom ook nie die merkers wat 'n latere hand gebruik het om die boek Genesis te konstrueer nie. Hiermee het die belangrikheid van die toledot-formules nie afgeneem nie.

Toledot kom tien keer heel prominent in Genesis voor (Gispen, 1966: 106; Harrison, 1970:545). Keil en Delitzsch 1949:35 e.v.) het dit weer beskou as die merkers waarvolgens Genesis gekonstrueer is. Holwerda (1971:14; cf. ook Kidner, 1968:59; Harrison, 1970:545) sluit hierby aan, alhoewel hy dit anders formuleer. Die meeste kommentare volg egter nie hierdie spoor nie, omdat toledot onreëlmatig oor die boek versprei is, en dit sou meebring dat die inhoud onnatuurlik in bepaalde blokke ingedwing sou word. Holwerda gaan egter verder en wil toledot nie bloot as 'n struktuurmerker gebruik nie. As Eissfeldt toledot insluit by 'n bewuste beplanning by die opstel van Genesis maar nie end-uit daarmee volhou nie (cf. Külling, 1964:222; Eissfeldt, 1958:34), tas Holwerda (1971:13) verder deur en stel: "Wanneer we dit in het oog houden, dat de toegevoegde genetivus aanduidt een nieuw beginpunt en toledot een eindpunt, immers een historisch resultaat, dan hebben we onmiddelijk begrepen, dat Genesis in sterkte mate een tendenzgeschrift is. En ook hebben we dan inzicht gekregen in de compositie van Genesis. De schrijuer geeft na het verhaal van de schepping achtereen- 
volgens tien van deze toledot. Fn het merkwaardige is, dat het eindpunt van toledot één tegelijk fungeert als het begin van toledot twee enz." Külling (1964:225) stem hiermee saam en beklemtoon: "Die Toledoth haben uns gezeigt, dass die ganze Genesis eine konstruirte 'Tendenzschrift' ist".

Om nog tot die gesprek toe te voeg: Die meeste van bogenoemde geleerdes beskou toledot as die begin van 'n nuwe Skrifgedeelte of historiese tydperk. Harrison (1970:547) beweer op voetspoor van P.J. Wiseman dat toledot egter op dit wat voorafgaan betrekking het. Wiseman (1958) neem toletot as die sleutelwoord aan die slot van 'n tablet. Kroeze (1967:9-10) meen ook dat toledot in Gen. 2:4a gepas die afsluiting van die skeppingsberig in Gen. 1 vorm.

Bogenoemde is genoeg om aan te toon dat dit wel lonend sal wees om weer oor die funksie van toledot te besin. Is toledot gebruik as merker of verindingskakel in Genesis of die openbaringsgeskiedenis? Ek wil aan die hand doen dat die funksie van toledot meer op die terrein van die sentrale tema van Genesis gesoek moet word. Dit het meer openbaringshistoriese as strukturele merkerwaarde.

Die begripsinhoud van die woord toledot is gebou op die stam ild of wld en het as selfstandige naamwoord 'n $t$-preformatief bygekry. Jld dui die baring by vroue aan, en as dit van mans gebruik word, beteken dit "verwerk". In oordraagtelike $\sin$ kan van voortbring gepraat word: 'n volk word voortgebring, 'n dag kan iets voortbring. Dit beteken ook tot stand bring: Ps. 90:2 vermeld dat God iets tot stand bring (cf. Koehler-Baumgartner (K-B), 1958; Kühlewein, 1971). Toledot is dan die resultaat van baring of verwekking. Ons kan volgens K-B daaronder die volgende begrippe onderskei: 1. Nachkommen, Sprössling, descendents. Holladay voeg by: (line) of descendants. 2. Generation, Zeitgenossen, generation, contempories, genealogy. 3. Entstehungsgeschichte, Geschichte, Entstehung, Erzeugung, begettings, Geburtsfolge, successive generations, met Holladay se byvoeging: story of development, - of generations, history, origin.

Gesenius-Tregelles dui die volgende aan: 1. Generations, families, races. 2. History, origin. 
Kühlewein merk Geschlechter en Geschlechtsgeschichte aan.

Holwerda verwys na Gesenius-Buhl: 1. Geschlechter, Sprösslinge. 2. Geschlechtsfolge oder allgemeiner: Geschlechtsgeschichte. 3. im uneigentl. Sinn: Hervorbringen des Himmels und der Erde. König spreek van 1. Zeugung, resp. Geburt. 2. meton. deren Product: Pl. a) Generation, Geschlechtsfolgen, Versweigungen; b) nochmals meton., indem Subjekte mehr oder weniger das mit ihnen Geschehen vertreten: Erlebnisse, Geschichte.

Aalders sê: "tholedôth duidt blijkens het Hebreeuse spraakgebruik niet aan de "geboorte" zelf, maar wat van het 'baren' het product is: veelvuldig de "nakomelingschap" of het "geslacht", en in enkele gevallen in nog ruimer zin: wat met die nakomelingschap gebeurt, m.a.w. de "geschiedenis". (Cf. Holwerda, 1971:11.)

By die vasstelling van die begrip toledot bou Holwerda (1971:12) veral op die grondbegrip jld - baar. Hy gee Aalders gelyk dat toledot die produk van die baringsproses is: dit wat voortgebring is, die resultaat, meesal kinders, maar dit het ook die betekenis van nakomelingskap, wat oordragtelik as historiese resultaat verstaan kan word (cf. Gen. 2:4). Hy wil geensins die begrip geskiedenis daaraan heg nie, omdat toledot as geskiedenis in vele konteksverbande in Genesis nie sou inpas nie. Gispen (1966:109), wat hoofsaaklik met Holwerda saamstem, meen egter dat geskiedenis in sekere plekke deur geen beter woord vervang kan word nie.

Voordat 'n gegripsvariasie-ondersoek in Genesis onderneem word, is dit interessant om op die statistiese voorkoms van toledot te let (cf. veral Kühlewein, 1971 I : 732-6). Die werkwoord $j l d$ kom 492 keer in die Ou Testament voor, waarvan Genesis die meeste bevat (170 keer). Toledot kom 39 keer voor, waarvan 13 keer in Genesis, 3 keer in Eksodus, 13 keer in Numeri, 1 keer in Rut en 9 keer in 1 Kronieke. Die ondersoek na die begrip toledot in Genesis moet met die 13 plekke in Genesis rekening hou en nic alleen met die 10-11 plekke waar dit prominent staan nie. Nege uit die 13 keer (ongeveer $70 \%$ ) word toledot ten nouste aan 'n genealogie verbind. Vergelyk: Toledot in die stamboom van Adam (Gen. 5:1-32). In die stamboom van die seuns van Noag (10:1-32) is dit opmerklik dat die stamboom sowel begin as afgesluit word met toledot. Die laaste woorde is: Dit is die geslagte van die seuns van Noag volgens hulle afstamming (letoledotam). So wys toledot aan die begin op wat volg, en aan die einde op wat voorafgegaan 
het. Die genealogie is omraam deur toledot en so onlosmaaklik daaraan verbonde. Toledot is verder aan die stamboom van Sem verbind (11:10-32). Toledot kom hier twee keer voor. Dit lei die eerste gedeelte in (v. 10), waar 'n lineêre patroon voorkom, maar in vers 27 trek toledot die aandag op 'n vertakking en uitbreiding in die genealogie. Vers 27-32 is nie 'n volgende genealogie nie maar ' $n$ vertakking en uitbreiding wat normaalweg in genealogieë voorkom. Dit het betrekking op Tera, en die gedeel te eindig dan ook met Tera. Die roeping van Abraham in Gen. 12 is openbaringsgeskiedenis en nie meer genealogie nie. In die stamboom van Ismael (25:12-18) kom toledot weer twee keer voor. In vers 12 word dit wat volg, as toledot aangedui $_{3}$ en in vers 13 word die klem op die individue gelê (toledotam). In die stamboom van Esau (36:1-19) kom toledot weer twee keer voor. Hier is die omgekeerde van Gen. 11. Eers word 'n vertakking en uitbreiding gegee met die inleidende toledot en van vers 9 af 'n inleidende toledot met 'n lineêre geslagslyn.

Die verband tussen toledot en die genealogieë word verder versterk deur die veelvuldige gebruik van die stam $j l d$ in die genealogieë. In Gen. 5:1-32 is die stam 27 keer verteenwoordig; in 10:1-32, waar dit om die volke gaan, 5 keer; in 11:10-32 $21 \mathrm{keer}$; in 36:1-19 7 keer. Bostaande bewys in baie opsigte die noue verbondenheid van toledot met die genealogieë. In sekere genealogieë kom die woord toledot nie voor nie (die van Kain (4:17-22); van Lot (19:36-38); van Nahor (22:20-24), van Abraham en Ketura (25:1-4); van die seuns van Seï (36:20-39); van die stamhoofde van Esau (36:40-43) en van die naamlys van die seuns van Israel (46:8-27)). Met die uitsondering van 46:8-27 het hierdie genealogieë op "randfigure" betrekking (in 25:1-4 val die klem nie op Abraham nie maar op Ketura). Die uitsondering 46:8-27 is 'n afwyking maar hoef nie die reël omver te werp nie.

Die vier van die dertien keer waarin toledot in Genesis voorkom en wat nog nie behandel is nie, is die toledot van die hemel en die aarde (2:4). Dit is moontlik dat dit sowel na die skeppingsberig in Gen. 1 as na dit wat daarna volg, kan heenwys (cf. die inleiding van hierdie artikel). In 6:9 het toledot te doen met Noag se optrede en sy geskiedenis wat daarna volg. Opmerklik is dat in vers 10 genealogiese gegewens gegee word. Hy het drie seuns gehad, Sem Gam en Jafet. So het die toledot van Isak in 25:19 ook genealogiese waarde. 'n Sekere terugwerkende lyn word gevolg: Abraham was die vader van Isak, en daarna volg 'n vertakte uitbreiding, naamlik die geskiedenis van die geboorte van Jakob en Esau. Genesis 37:2 noem die toledot van Jakob, maar die verrassende is dat nadat dit aangekondig is, die 
geskiedeni's van Josef volg, en as na Jakob verwys word, hy nou lsrael genoem word. Gen. 37:2 kan egter 'n heel gepaste slot vorm van die geskiedenis wat in 28:10-35-29 voorafgegaan het. Die skrywer van Genesis het heel gepas geoordeel om na 35:29 eers die stamboom van Esau, die ander broer, te gee, voordat hy met Josef aangaan. So vorm Gen. 36 as geheel 'n afwyking van die geskiedkundige voortgang van Jakob, en die skrywer moes in 37:1-2 die lyn weer hervat.

Die verklaring van die begrip toledot in sy semasiologiese verband, wat belangriker is as die etimologiese verklaring (die produk van baar) maar daarsonder ook nie volledig is nie, hou die volgende in:

1. Nageslag, geslag, afstamming. In Gen. 10:32 word opsommenderwys na die kinders van Noag verwys soos wat hulle van Noag afgestam het. Vergelyk hier ook 25:13. In Num. 1 word die 12 seuns van Jakob en hulle nakomelinge genoem. Kyk ook na Eks. 6:16,19. In Eks. 28:10 word die stamme self as toledot getipeer. Hierdie begrip funksioneer primêr in die boek Kronieke (cf. 1 Kron. 5:7; 7:2,4,9; 8:28; 9:9,34).

2. Nageslags- of geslagslyn, geslagsregister, genealogie. Dit is wesenlik dieselfde as punt 1 , behalwe dat die klem nie meer op die individu val nie. Die name van die nageslag word saam in een groot verband saamgevoeg. Dit is objektiewer, en 'n aparte genre het ontstaan. Vergelyk hier die stamboom of geslagsregister van Adam (5:1-23), die kinders van Noag (10:1-32) ens. Die struktuur van die genealogieë wissel soos die diepte (die getal name wat genoem word) en die aard van die geslagslyn (reguit of lineèr, vertak of horisontaal, met of sonder historiese uitbreiding). Die historiese uitbreiding vorm juis die oorgang na die volgende begripsnuanse, naamlik die oordragtelike en meer historiese betekenis. Vergelyk die voorbeelde wat reeds genoem is, naamlik die uitbreiding in $11: 27-32$ en $36: 1.8$.

3. Die oordragtelike betekenis: geslagsgeskiedenis of geskiedenis. In aansluiting by punt 1 het toledot ook die begrip "geskiedenis" verkry. Dit het wel te doen met ontstaan en kan as "ontstaansgeskiedenis" of "gcslagsgeskiedenis" omskrywe word (cf. Büchsel, 1964:683 - "The formula eelleh toledot is used to introduce genealogies or historical narratives (Gen. 6:9; $37: 2$ ) or the two together"). So word die geboortegeskiedenis van die hemel en aarde in Gen.2:4a aangedui. In 6:9 e.v. word die toledot van Noag aangekondig, en alhoewel sy seuns se name in vers 10 genoem is, volg die optrede van Noag. So pas "geskiedenis" ook by 25:19 en veral by 37:2. 
'n Voorlopige gevolgtrekking is dat toledot die klem op die geslagte en in besonder op die geslagslyste laat val. Die geslagsgeskiedenis is die oordragtelike sin, wat semasiologies bevestig word. Dit is veral die begingeskiedenis van die eerste persone (aartsvaders) wat die HERE as sy openbaringshistoriese instrumente wou gebruik.

Hiermee moet die waarde van die geslagte, geslagslyste en die geslagsgeskiedenis nie onderskat word nie. Genealogieë is self die begin van geskiedbeskrywing, dit is embriogeskiedbeskrywing, want dit bevat die skema waarlangs die geskiedenis van God se openbaring aan en in sy geroepe persone geloop het. Waar dit van belang is, is historiese uitbreiding gegee, en waar persone se optrede nie van belang is nie, is hulle name selfs uitgelaat. Deur die genealogieë is dit egter moontlik om lang historiese tydperke te oorbrug. Die verskillende persone wat genoem is, toon 'n verwantskap en 'n verwantskapslyn, of, beter gestel, die verbondslyn word so deurgetrek. (Vgl. vir die funksie en struktuur van die genealogieë Johnson, 1975 en 1977; Harris, 1975, en Mitchell, 1976.) Toledot het dus ook nou vetrekking op die openbaring van God in die begingeskiedenis.

Iolwerda (1971:13) het vir toledot 'n plek in die gang van die openbaringsgeskiedenis ingeruim: "het merkwaardige is, dat het eindpunt van toledot cen tegelijk fungeert als het begin van toledot twee enz." Die toledotformules is dan openbaringshistoriese merkers sonder dat daar tydgapings tussen die merkers voorkom. Dit vorm 'n kontras met die feit dat toledot meesal tot 'n bepaalde genealogie of tot die onmiddellike geskiedenis daaromheen beperk is. Holwerda het sy opvatting op die 10 prominente toledot-formules in Genesis gebaseer, terwyl daar 13 is. In besonder bespreek hy dan Gen. 2:4, 11:27, 25:9 en 37:2 maar 5:1, 6:9 e.a. word verbygegaan. Die toledot van Noag in 6:9 handel juis oor dic geskiedenis van Noag en nie oor sy kinders nie. Ilolwerda se bewering dat die toledot van 'n persoon nie oor sy eie optrede handel nie maar oor een wat uit hom voorgekom het, hou dus nie steek nie. Die toledot in 36:9, kort na die een in 36:1, kan ook moeilik die begin of einde van 'n nuwe tydperk aandui. In Gen. 10 en 25:12-18 kom toledot elke keer twee keer voor sonder om 'n nuwe tydvak aan te dui. Toledot lê hier juis op kleiner besonderhede van die openbaringsgeskiedenis klem. Dit is duidelik dat dit nie moontlik is om die cydperkc in Gen. 25:12-18 en 25:19-20 as twee opeenvolgende tydperke te sien nie, want Ismael en Isak was tydgenote. Dieselfde geld van die tydperke van lisau (Gen. 36:1-19) en Jakob (37:2). Holwerda het te min rekening gehou met die plek van die genealogieë en die inherente verband van toledot met 
die genealogië

Waarin mọet die funksie van toledot dan gesoek word? Dit is eerstens vir die Oosterling belangrik dat die openbaringsfigure in ' $n$ lang ketting van geslagte aanmekaar gesmee moet word (cf. Van Selms, 1967:47). Die geslagte en geslagslyste openbaar die wil van God. In Genesis is daar ander kettingwoorde en refreine wat in berekening gebring moet word.

Van Zyl (1971:63) het die aandag op die refrein "wees vrugbaar en vermeerder" gelê $(1: 28 ; 8: 17 ; 9: 1,7 ; 17: 6,20 ; 26: 22 ; 28: 3 ; 35: 11 ; 41: 52$; $47: 27 ; 48: 4)$. Dit het met voortplanting, die voortbring van geslagte te doen. Westermann (1967:13) beskou Deut. 34:1-4 as die sleutel om die Pentateug, soos dit uiteindelik saamgestel is, tot 'n eenheid te bind. Die laaste woorde van die HERE aan Moses was: "Dit is die land wat Ek aan Abraham, Isak en Jakob met 'n eed beloof het met die woorde: Aan jou nageslag sal ek dit gee". Die lands- en nageslagsbelof te word beklemtoon. In Jenesis neem die verbond met sy beloftes 'n sentrale plek in (cf. 12:1,2; $15 ; 17 ; 26: 1-5 ; 28: 5-22 ; 35: 1-15)$. Die verbondsbeloftes het betrekking op 'n land, 'n nageslag, 'n goeie naam, die seën vir ander nasies, die ewigheid van die verbond, die konings wat uit die nageslag sal voortkom, en op God se gemeenskap met Abraham en sy nageslag (Lion-Cachet, 1977:151-165). Die lands- en nageslagsbelofte staan in Genesis pertinent voorop (cf. 12:1-2; $15: 5,18-22 ; 17: 2-6,8$, ens.). Met reg kan gesê word dat die verbondsluiting en die verbondsbeloftes wat op die land en nageslag betrekking het, in Genesis sentraal beklemtoon word (cf. Clines, 1978, met sy konklusie dat die tema van die Pentateug die gedeeltelike vervulling van die beloftes aan die patriarge is).

In die lig van bogenoemde is die funksie van toledot maklik te bepaal. Die paradysbevel van God aan die mens is: "Wees vrugbaar en vermeerder en vul die aarde" (1:28). In die verbond met die mens belowe Hy dat Hy hulle vrugbaarheid sal seën: hulle sal wees soos die sterre van die hemel (15:5), en 'n menigte nasies sal uit hulle voortkom (17:4). Ten spyte van die sondigheid van die mens, wat sy verpligtinge in die verbondsverhouding nie nakom nie en daardeur die wraak van God oor sy eie voortbestaan inroep, sodat die verbondskind in die begingeskiedenis telkemale met algehele uitwissing bedreig word (die moord op Abel, die sondvloed, die onvrugbaarheid van Sarai, Rebekka en Ragel, die eis om Isak te offer, Esau se bedreiging om Jakob dood te maak, die hongersnood wat die kinders van Israel na Egipte uitdrywe), staan die verbondsbeloftes van die HERE onwrikbaar vas. Van 
die paradys af is daar 'n geslag en 'n geslagsgeskiedenis van die met wie God sy verbond gesluit het. Toledot beklemtoon die rivier van God se genade wat van die paradys af voortvloei deur baie woestyne waarvan niemand iets weet nie en baiekeer vir die menseoog onsigbaar is maar eeue lank konstant bly, totdat Israel in Egipte 'n magtige nasie geword het: "(Hulle) was vrugbaar en het baie geword, en hulle het vermeerder en buitegewoon magtig geword, sodat die land vol was van hulle" (Eks. 1:7). Toledot dui ook sommige sytakkies aan, soos die geslagsgeskiedenis van Ketura, Esau ens., waarvan baie in die woestynsand verdwyn het.

So gesien het toledot 'n baif belangrike funksie, deurdat dit die eenheid van die sentrale openbaringslyn in die begingeskiedenis (Genesis) deurtrek. Dit is nie maar die paar bakens op die trekpad nie, maar dit oorbrug God se genade van die paradys tot in Egipte. Dit dui die kontinuiteit van sy belofte aan om aan sy kinders 'n nageslag te gee.

\section{AANGEHAALDE BRONNE}

BüCHSEL, F. 1964. Genesis. (In Kittel-Bromiley: Theological Dictionary of the New Testament. Grand Rapids, Eerdmans).

CLINES, D.J.A. 1978. The theme of the Pentateuch. J.S.O.T. Supplement Series 10.

GISPEN, W.H. 1966. Schepping en paradijs. Kampen, Kok.

IIARRIS, R.L. 1975. Genealogy. (In Tenney: The Zondervan Pictorial lincyclopedia of the Bible. Grand Rapids, Zondervan).

HARRISON, R.K. 1970. Introduction to the Old Testament. London, Tyndale.

HOL,WERIAA, B. 1971. Historia Revelationis Veteris Testamenti. Kampen, Van den Berg.

JOHNSON, M.D. 1969. The purpose of Biblical genealogies. Cambridge, University Press.

KIDNER, D. 1968. Genesis. London, Tyndale. 
KROEZE, J.H. 1967. Die tuin van Eden. Pretoria, N.G. Kerk-boekhandel.

KüHLEWEIN, J. 1971. Jld, gebären. (In Jenni-Westermann : Theologisches Handwörterbuch zum Alten Testament. München, Kaiser.

LION-CACHET, F.N. 1977. Abraham en Sinai. Potchefstroom. Ongepubliseerd.

MITCHELL, T.C. 1962. Genealogy $\therefore$, In Douglas, J.D. The New Bible Dictionary. London, Intervarsity Fellowship.

VON RAD, G. 1963. Genesis. London, SCM.

VAN SELMS, A. 1967. Genesis I. Nijkerk, Callenbach.

VAN ZYL, H.A. 1971. Gods Woord in menstaal I. Pretoria, N.G. Kerkboekhandel.

WESTE RMANN, C. 1967. Handbook to the Old Testament. Minnea ' lis, Augsburg Publishing House.

WILSON, R.R. 1975. The Old Testament genealogies in rucml rescarch. Journal of Biblical Literature, jrg. 94:169-189.

WILSON, R.R. 1977. Genealogy in history in the Biblical world. New Haven, Yale Univ.

WISEMAN, P.J. 1958. New discoveries in Babylonia about Genesis. London, Marshall, Morgan \& Scott.

WOUDSTRA, M.H. 1970. The toledot of the book of Genesis and their redemptive-historical signifance. Calvin theological journal, jrg. 5: 184-189. 